\title{
Simulation and Test Analysis on Mechanical Property of GCG-I Platform Wagon Coil Steel Pallet
}

\author{
DunhuaLiu ${ }^{1, a}$, MeiHan $^{1, b}$ and NengpuYang ${ }^{1, c}$ \\ ${ }^{1}$ School of Beijing Jiaotong University, Beijing100044, China; \\ astar_Idh@163.com, bmhan@bjtu.edu.cn, yangnengpu@163.com
}

Keywords:Coil steel pallet, Mechanical property, FEA; Shock.

\begin{abstract}
This paper focus on simulation on mechanical property of platform wagon GCG-I coil steel pallet by using computer simulation technology and compare calculated value with the result in actual situation. The dimension model is built by SolidWorks. The value of various parameters is determined by the force analysis according to the relevant standard in working condition of shock. Do finite element analysis by hypermesh and do finite element simulation on mechanical property by Ansys. By comparing the calculated value with the result in the actual situation, we can conclude that this coil steel pallet is unqualified and prove the reliability of simulation and that the computer aid analysis can be used in the coil steel pallet detection in order to decrease the cost and increase the accuracy.
\end{abstract}

\section{Introduction}

Railway cargo transportation loading and reinforcement is closely linked to transportation safety and high efficient and economic transport task. Reinforcement affects not only the transportation safety of the goods itself but also the operation safety of the train. With the increase of coil steel volume and the improvement of freight train driving speed, the loading and reinforcement of coil steel is always the focus of the railway goods transportation research considering the particularity of appearance. Currently coil steel pallet is mostly used, its convenience, recycling use and protection to coil steel makes it welcomed.

Every new coil steel pallet need to detect after designing, including strength testing. In this strength testing, only measuring points can be tested, so selecting suitable points is critical to accuracy of test.

Taking GCG-I coil steel pallet as an example, this paper use professional software to conduct joint simulation analysis. Comparing former testing, three professional software are used in order to improve accuracy. The finite element analysis which can provide reference in the real testing measurement is useful and significant.

\section{Testing Process}

During operational process, shunting impact is considered as the most unfavorable condition and also determined as test condition of strength test. Process is considered safe as long as the impact process is safe.

According to the regulation of strength test, the process include measuring point arrangement, strain gauge paste, measurement circuit connection, debugging the tester, data collection and data processing. Actual testing scheme is in Figure 1. The No.1 coil steel pallet is balance weight and the No. 2 coil steel pallet is test object. 


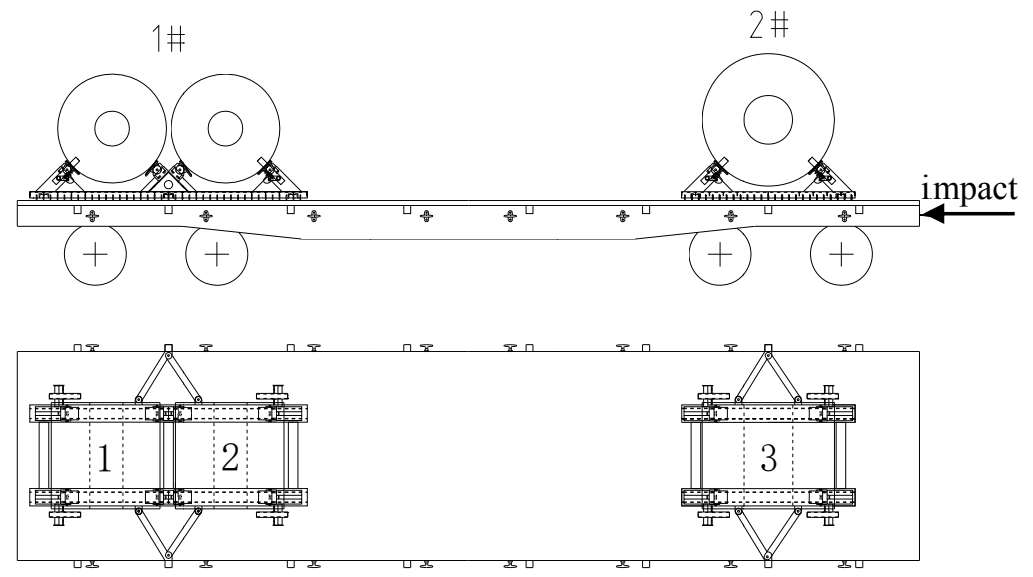

Figure 1Actual testing scheme

\section{Force analysis}

The force situation of coil steel pallet in impact condition is complex, in order to simplified calculation, ignore wind power and lateral force of friction and so on which have little influence.

Assumption 1.the weight of the pallet, the horizontal inertia force and the braced forceof the pallet is calculated. The force analysis as the Fig.2.1 shows the force of the pallet.
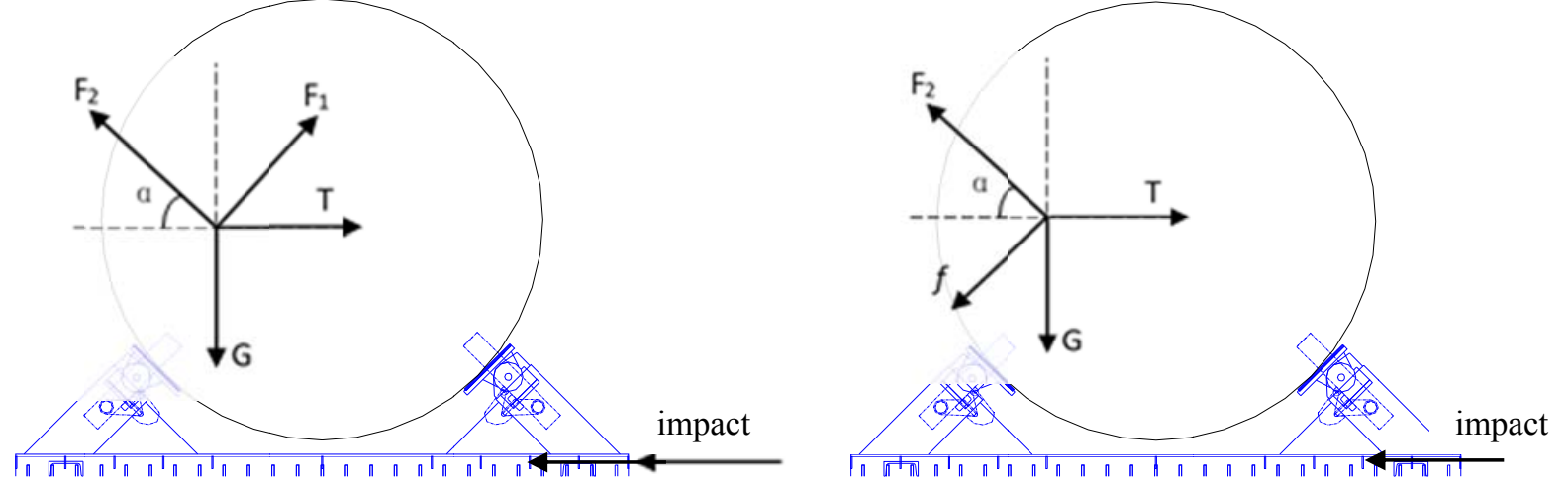

Figure 2.1Actual testing schemeFigure 2.2Actual testing scheme

$F_{1} 、 F_{2}$ - force of bracing, $\mathrm{kN}$;

$\mathrm{G}$ - - weight of the coil steel,kN;

$\alpha$ - - angle of the bracing, $45^{\circ}$ in the design parameter;

$\mathrm{T}$ - - vertical inertial force, $\mathrm{kN}$;

$F_{1} \cos \alpha+F_{2} \sin \alpha=G=\operatorname{Qg}$ (1)

$F_{2} \cos \alpha-F_{1} \sin \alpha=T=\mathrm{Q} t_{0}$ (2)

The acceleration of the rolled-steel was calculated as the rule in the $<$ Rules of Railway Loading Security $>$ in the impact condition which belongs to the flexible stabilization, the calculation form as follows:

$$
t_{0}=0.0012 Q_{\text {总 }}^{2}-0.32 Q_{\text {总 }}+29.85(3)
$$

In order to simulatethe most unfavourable condition, set $Q_{\text {卷钢 }}$ to $30 \mathrm{t}, Q_{\text {座架 }}$ to $1.3 \mathrm{t}$, and $Q_{\text {车 }}$ to $1.3 \mathrm{t}$, then $t_{0}=11.41 \mathrm{kN} / \mathrm{t}$. Thus $F_{1}$ is found as negative after calculation. So the coil steel is fixed by one sidebraced force.

Assumption 2.the weight of the pallet andthe horizontal inertia force and the one side braced force of the pallet is calculated.It's clearly to calculate that the force is unbalanced.

Assumption 3.the weight of the pallet,the horizontal inertia force, the one side braced forceand friction force of the pallet is calculated.The force analysis as the Fig.2.2 shows the force of the pallet. $F_{2} \sin \alpha-f \cos \alpha=G=\operatorname{Qg}$ (4)

$F_{2} \cos \alpha+f \sin \alpha=T=\mathrm{Q} t_{0} \quad$ (5) 
According to formula, $F_{2}=449.9 \mathrm{kN}, f=34.2 \mathrm{kN}$. The load is set as force analysis above in the software Ansys.

\section{Displacement analysis}

According to the former experience of shunting impact test, coil steel and pallet is difficult to overturn. The lengthwaysdisplacement and horizontal displacement are restricted by spike and the vertical displacement is restricted by wood floor. So in software Ansys, the chassis of pallet is fixed to wood floor.

\section{Coil Steel Pallet Modeling}

GCG-I coil steel pallet consist of fixed mounting base, classis channel steel, reinforcing rib and join channel steel. In the process of transportation, two fixed mounting base bear strength collectively and coil steel don't tough classis.

According to the ideas of the finite element, do mesh generation first. Considering this coil steel pallet is belong to shell structure, this paper use neutral plane model and shell element to mesh. Neutral plane model has advantage of high calculate speed and low requirement of computer hardware, especially for shell structure. After a series of depose, the model is meshed into 62024 elements. The stress nephogram getting from Ansys is like Figure 3.

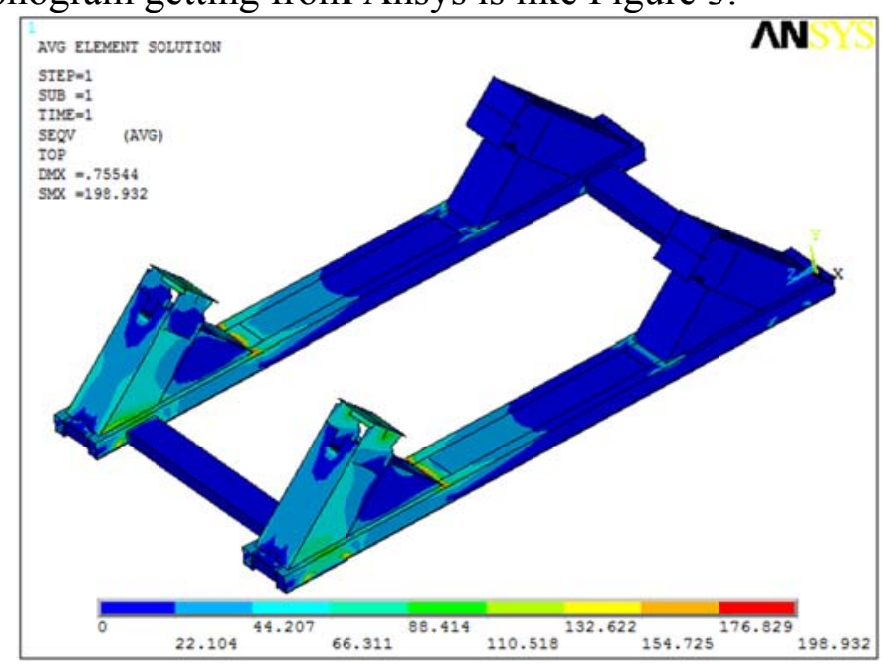

Figure 3 stress nephogram

\section{Comparison analysis}

According to the results of simulation and experience in everyday work, the measuring point is determined as shown in Figure 4. 

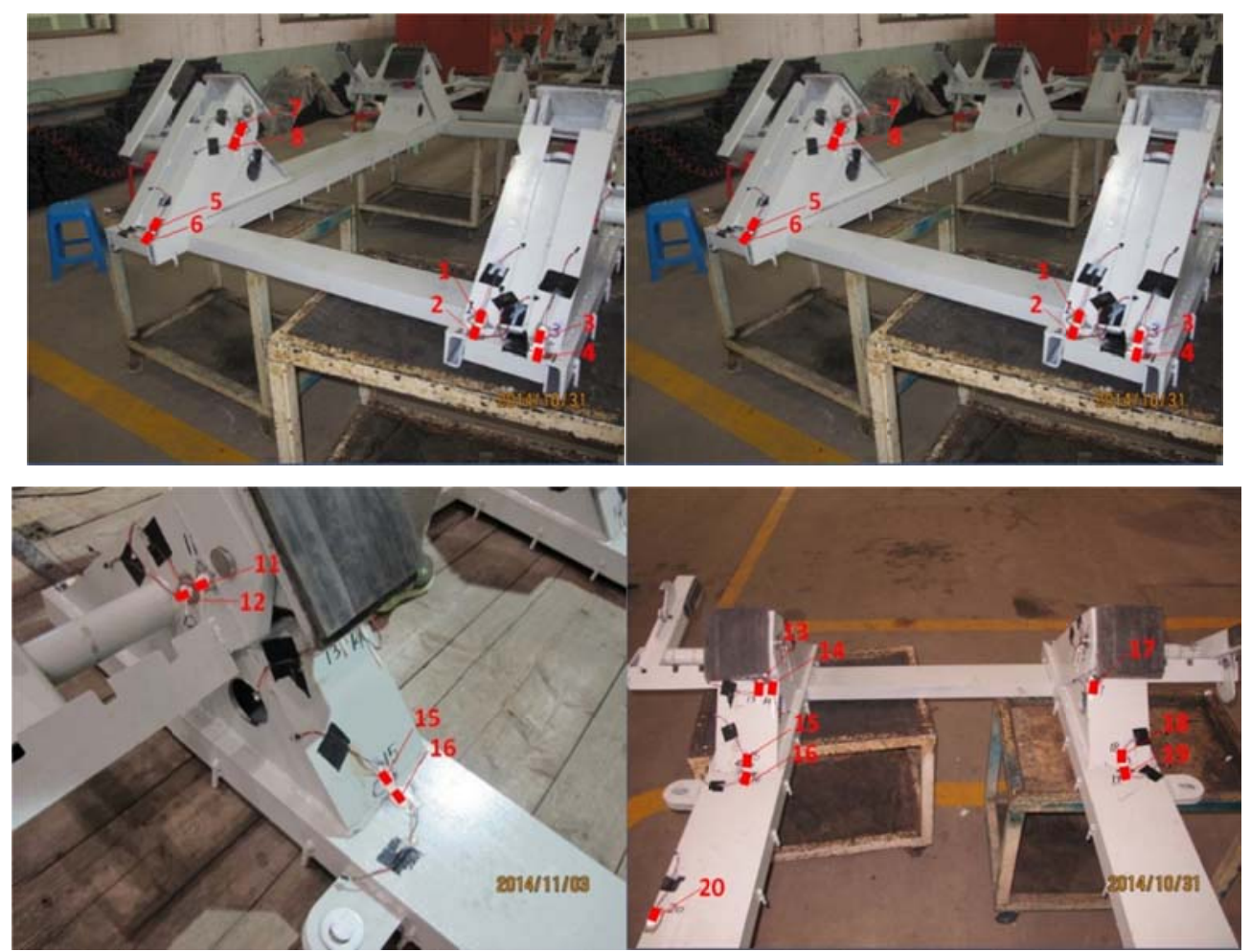

Figure 4 the measuring points

Considering the computing method of inertia force, in order to reduce the error, compare experimental data of $6 \mathrm{~km} / \mathrm{h}$ to simulation data, as follows.

Tab.1 comparison of measured and calculated values of each measuring point

\begin{tabular}{|c|c|c|c|c|}
\hline NO. & $\begin{array}{l}\text { Measured } \\
(\text { Mpa })\end{array}$ & Calulated（Mpa） & $\begin{array}{c}\text { Abs.difference } \\
\text { (Мpa) }\end{array}$ & Notes \\
\hline 1 & 18.6 & 23.9 & 5.3 & symmetric with No.5 \\
\hline 2 & 2.7 & 19.9 & 17.2 & symmetric with No.6 \\
\hline 3 & -21.0 & -19.9 & 1.1 & \\
\hline 4 & -25.4 & -23.7 & 1.7 & \\
\hline 5 & 37.8 & 21.5 & -16.3 & symmetric with No. 1 \\
\hline 6 & 17.7 & 17.9 & 0.2 & symmetric with No. 2 \\
\hline 7 & -76.1 & -21.9 & 54.2 & symmetric with No.9 \\
\hline 8 & -24.7 & -20.4 & 4.3 & symmetric with No. 10 \\
\hline 9 & -24.9 & -24.6 & 0.3 & symmetric with No.7 \\
\hline 10 & -25.8 & -25.3 & 0.5 & symmetric with No.8 \\
\hline 11 & -22.9 & -28.6 & -5.7 & \\
\hline 12 & -13.0 & -22.1 & -9.1 & \\
\hline 13 & -7.8 & -10.8 & -3 & \\
\hline 14 & 49.9 & 40.2 & -9.7 & symmetric with No. 17 \\
\hline 15 & 37.7 & 40.1 & 2.4 & symmetric with No. 18 \\
\hline 16 & 193.6 & 190.4 & -3.2 & symmetric with No.19 \\
\hline 17 & 68.3 & 44.6 & -23.7 & symmetric with No. 14 \\
\hline 18 & 55.3 & 43.6 & -11.7 & symmetric with No. 15 \\
\hline 19 & 217.3 & 205.4 & -11.9 & symmetric with No. 16 \\
\hline 20 & 68.2 & 25.8 & -42.4 & \\
\hline
\end{tabular}




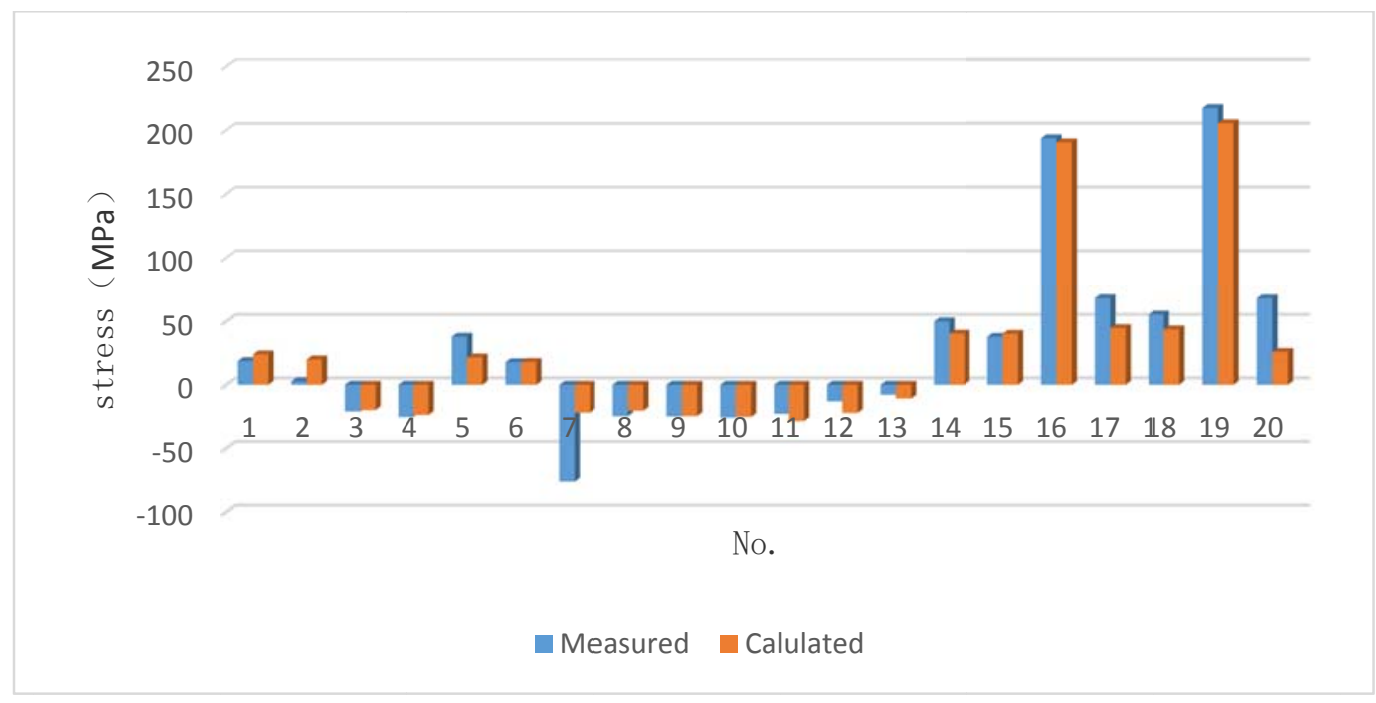

Fig 5. measured and calculated values

Some conclusion is got through the analysis of the table and figure:

A. According to comparison, most measured and calculated values is similar to each other expect No.2, No.5 No.7 and No.20. But the calculated value of No.2, No.5 and No.7 is similar to their symmetry points'. The calculated results are relatively accurate.

B. The pallet is symmetrical structure, when applying load symmetrically, the calculated value is almost symmetrical. And it's all because the arithmetic of automesh that the mesh is not completely same in symmetrical position.

C. The value of several symmetrical points is much different, such as No.7 and No.9, the gap is up to $51.2 \mathrm{MPa}$. The reason is perhaps bulk movement of pallet, coil loading not centered, asymmetrical position of strain gages and manufacturing incident.

D. In the actual test, maximum working stress appears in No.19, the value is $217.4 \mathrm{MPa}$. in simulation, the maximum stress also appears in the same position, the value is $205.4 \mathrm{MPa}$. The gap is only $11.9 \mathrm{MPa}$.

In conclusion, finite element modelaccord with the actual test. It's confirmed that the model is reasonable and the calculation is accurate.

\section{Influence factor}

From the results below, the deviation is due to the follow five factors:

A. Difference between and model and reality: The real mount is a little different from the design paper. Because of workmanship, these steel structure is not completely smooth. And In the simulation modeling, simplify the model and ignore some portion that cannot be disposed.

B. Difference of constraint: When considering constraint, the strength and bond stress of spike. Assume that spike can completely restrain coil steel pallet.

C.coil loading not centered: In the real test, loading and unloading coil steel is operated by man. Observer is also judged eye whether the coil mediate or not. off-centralizing will cause different load of symmetry points, then stress will be different.

D. Different environment of simulation and test: When testing, many factors influence measured values, including uneven floorboard, the weather, stamp the testing wire, pallet striked and extruded by coil steel and so on.

E. Difference between position of strainmeter and simulation: Reading-off position in simulation model is different from the real position of strainmeter, which will cause the difference between measured and calculated. 


\section{Summary}

This paper set up entity model of coil steel pallet by Solidworks, do mesh generation by hypermesh and calculate by Ansys, based on finite element simulation. By comparing the measured value and calculated value, it's concluded that stress distribution of calculation and real test.As a whole, the model is reasonable that confirmed the accuracy of simulation calculation. At last, this paper analyses the five factors that contribute to the gap.

\section{References}

[1] Junping Gao. Study on Simulation Analysis and Test of Strength of Rolled-steel Pallet Transportation by Railway [D]. Beijing Jiaotong University, 2012.

[2] People's Republic of China Railway Industry Standard. TB/T 2369-2010, Impact test method and specification of rolling stock [S]. China Railway Press, China 2010.

[3] Ministry of China Railways: Rules of Railway Loading Security [S], China Railway Press, China 2006.

[4] Fang Zhe.Han Mei.Li Yuyi.Study on Finite Element Analysis of the Rolled-Steel Pallet Based on Ansys[C].Yoshinori Hayafuji.Xibing Li.Engineering Research and Designing for Industry.Qiqihar.2013. Switzerland.Trans Tech Publications Ltd.2013.66 72.

[5] Jinsong Li. The thoughts of using the roll-steel pallet in railway roll-steel transportation [J].Railway Transportation, 2012(4):34-38. 